\title{
THE MECHANISM OF THE SIGNS AND SYMPTOMS OF MITRAL VALVE DISEASE
}

\author{
BY \\ RICHARD GORLIN
}

From the Peter Bent Brigham Hospital, Boston, U.S.A., temporarily working at St. Thomas's Hospital, London

Received May 14, 1954

In the past four years there has been a renewed interest in the rather common problem of mitral valvular disease. This has been stimulated mainly by the recent remarkable advances in cardiac surgery (Bailey, 1949; Baker et al., 1950; and Harken et al., 1951). In fact, so much has been said, written, and conjectured on this subject that one feels a little diffident to open yet another discussion. It seems justifiable to do so nevertheless, if perhaps a more practical comprehension of the disease might be forthcoming. Now that specific therapy is available-but therapy which carries 5-15 per cent mortality of its own-attention must be given to more accurate diagnosis and appraisal. Because he possesses the reservoir of patients, responsibility for this rests heavily upon the medical consultant.

One must consider two aspects-first the type of valvular lesion, second its severity and complications. Our group believes that the pathologic physiology and clinical manifestations of mitral disease are intimately related (Gorlin and Gorlin, 1951; Gorlin et al., 1951 $a$ and $b$ and 1952; and Lewis et al., 1952); if one understands the former, the latter may be interpreted properly. It is not within the scope of this paper to discuss differential diagnosis: certain aids will emerge from the relation of physiology to symptoms but differential diagnosis needs also the aid of careful auscultation, screening, and electrocardiography.

The symptoms of mitral disease run the gamut from none at all to dyspnœa, orthopnœa, hemoptysis, œdema, ascites, hepatomegaly, and fatigue. These may be grouped as primarily pulmonary or systemic congestive, or general in type. And this grouping is important. It is not known why one patient may have more of one symptom than another within a group, but about the origin of any one group of symptoms versus another something can be said. Let us consider predominantly pure mitral stenosis first.

Acute pulmonary œdema, acute dyspnœa, or orthopnœa have not infrequently occurred during cardiac catheterization of patients with mitral disease. In our experience these patients always had an unusually high pulmonary capillary pressure, upwards of $30 \mathrm{~mm}$. $\mathrm{Hg}$, the normal being 5-10 $\mathrm{mm}$. It is presumed that either the vascular distension or the transudation of fluid into alveoli or their walls evoked pulmonary symptoms of varying degrees. So our first consideration is why this pressure is raised in mitral disease.

Pulmonary capillary pressure is dependent for its level on left atrial pressure which in turn depends on the mitral valve and left ventricular diastolic pressure. The mitral valve is a fixed orifice; the normal area is $5 \mathrm{sq}$. $\mathrm{cm}$. In disease it may be anything from this to $0.5 \mathrm{sq} . \mathrm{cm}$. or less in area. Fixed orifices impose certain conditions on fluids flowing through them. The amount of pressure necessary to force a given amount of blood through depends on the size of the orificethe smaller the valve the more pressure required. This is defined quantitatively in Fig. 1 which relates all three. On the abscissa is plotted pulmonary " capillary" pressure, an index of left atrial 


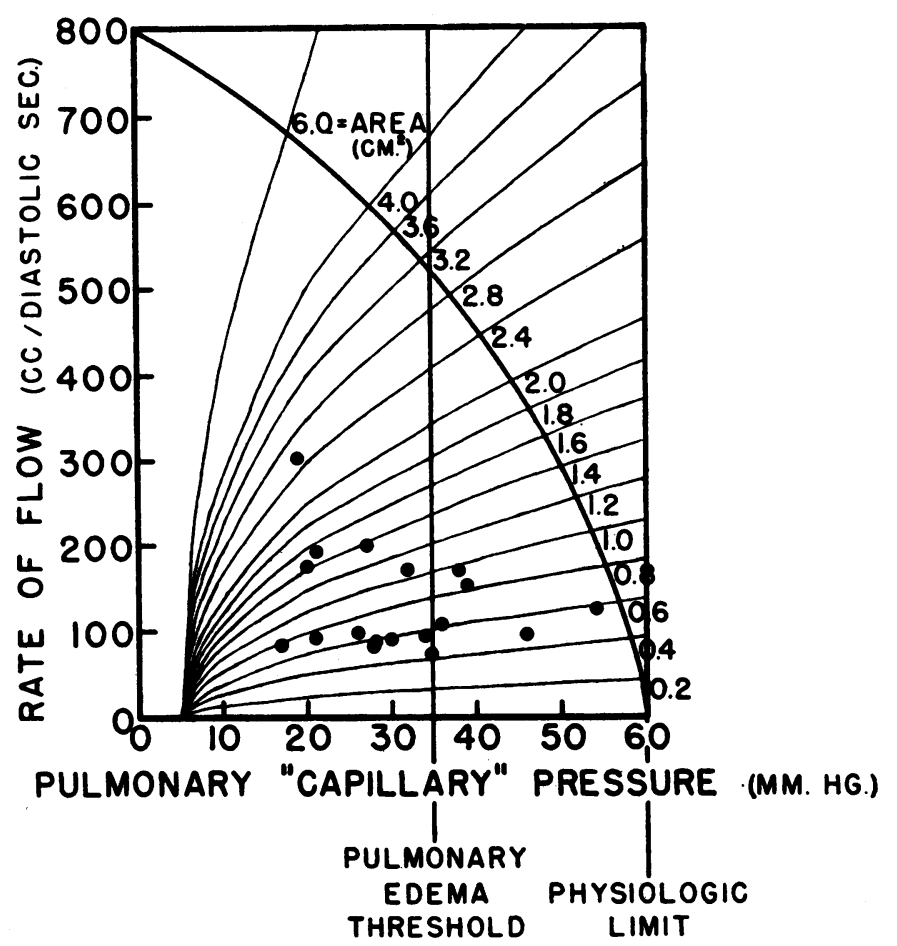

Fig. 1.-Relation of pulmonary capillary pressure to rate of valvular flow and valve area. Observed values are plotted against a background of theoretical pressure-flow for given areas. Reprinted from Gorlin and Gorlin (1951).

pressure; on the ordinate, the rate of flow through the valve during the time it is open in diastole. Each curve is the pressure flow relationship for a different valve area. Normal capillary pressure is up to $10 \mathrm{~mm}$.: the vertical line at $35 \mathrm{~mm}$. Hg indicates the pulmonary odema level; this occurred in each of the patients to the right of the line. Normal rates of flow, i.e. resting cardiac output and rate, are $150-250 \mathrm{ml} / \mathrm{sec}$. When the valve is normal in size, $5 \mathrm{sq}$. cm., huge flows can be handled without a great rise in pressure. When there is mild stenosis, pressure is mildly raised at rest but flows must rise to a considerable level before pressure exceeds $35 \mathrm{~mm}$. In these people, ordinary but not excessive exertions are easily performed. When the valve is $1.5 \mathrm{sq}$. cm., flow rates up to $250 \mathrm{ml} . / \mathrm{sec}$ - - a generous rate - can be tolerated, but certainly little more. These subjects usually have no symptoms at rest or on mild activity, but exertion will always result in dyspnoea or its equivalent. When the valve is $1 \mathrm{sq} . \mathrm{cm}$. or less, 20 per cent of normal, the classical tight stenosis, the relation of pressure to flow is very flat. A low normal flow rate of $150 \mathrm{ml} / \mathrm{sec}$. is barely tolerated. Any effort will result in symptoms. If the area is $0.5 \mathrm{sq} . \mathrm{cm}$., cardiac output must be much less than normal if pulmonary odema is to be avoided. Symptoms may often be constantly present. In tight stenosis the hazard of rapid heart action is great. This is the commonest cause of pulmonary œdema. When the heart rate speeds up more time is used for systole and less is left for diastole and flow through the mitral valve. Normally this matters little, but with a stenosed valve every moment of diastole counts. Blood must then go faster; left atrial pressure is increased to accomplish this; and pulmonary cedema often results from the raised pressure.

If one checks this hypothesis by actually plotting symptoms against valve area (Fig. 2) statistical verification is obtained. Thus we see first a qualitative relationship between height of pulmonary capillary pressure and pulmonary cedema and a quantitative relationship between degree of stenosis and severity of symptoms of dyspnoa, etc. 

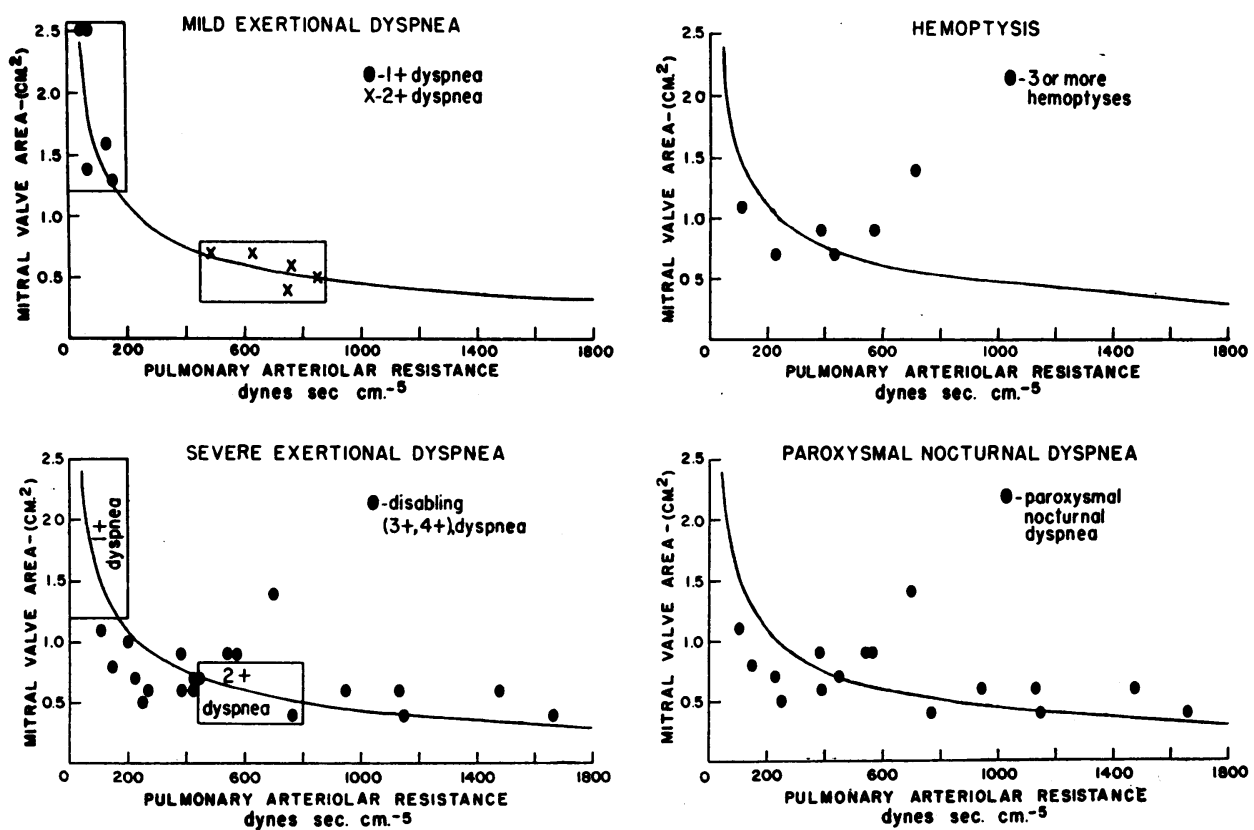

FIG. 2.-Relation of mitral valve area and pulmonary arteriolar resistance to pulmonary symptoms in mitral stenosis. Reprinted from Lewis et al. (1952).

Now if this tight stenosis and pulmonary capillary hypertension persist over a long period of time, organic changes often develop in the pulmonary end arteries, seen pathologically as narrowing of the lumen by a thickened wall and physiologically as an increase in calculated pulmonary vascular resistance. This resistance may be 10 to 15 times normal. As such it constitutes an obstruction to blood flow often worse than that at the mitral valve. Pulmonary arterial pressure rises behind the obstruction and flow through it decreases. Thus two obstructions raise pulmonary artery pressure and decrease cardiac output. The high pressure puts a load on the right ventricle, which may have to pump at a pressure five times normal against a pulmonary resistance ten times normal and this is almost always accompanied by evidence of right ventricular hypertrophy.

For a while this load is handled effectively. To the patient already limited by dyspnœa is added severe pulmonary hypertension, which may effect further dyspnœa, although this symptom has actually been known to decrease due to the lowered amount of blood having to go through the mitral valve. This so-called balanced circuit may result, wherein pulmonary pressures are stabilized but the right ventricle is still competent. This may last months or years.

Finally the right ventricle dilates, and congestive failure sets in with its usual manifestations of persistent jugular venous hypertension, œdema, and hepatomegaly. A good correlation was evident between these symptoms and the combination of severe stenosis plus raised resistance (Fig. 3).

Thus with this concept one can understand the long course of mitral stenosis, wherein a murmur persists for years without any incapacity. The valve is distorted, then stenosed, but not critically so till it is less than 25 per cent of normal in size. Then come the bouts of pulmonary symptoms, usually precipitated by exertion or emotion, or in relation to tachycardia, infection, infarction, pregnancy, anæmia, or thyrotoxicosis. The patient is usually quite well in between episodes. But if the valve becomes more stenosed, episodes become more common. Eventually auricular fibrillation and pulmonary vascular disease set in. Things can appear better for a while, due to the restriction of blood flow, but eventually the strain of pulmonary hypertension on the right ventricle and the low cardiac output inexorably lead to peripheral congestive manifestations. Edema, 

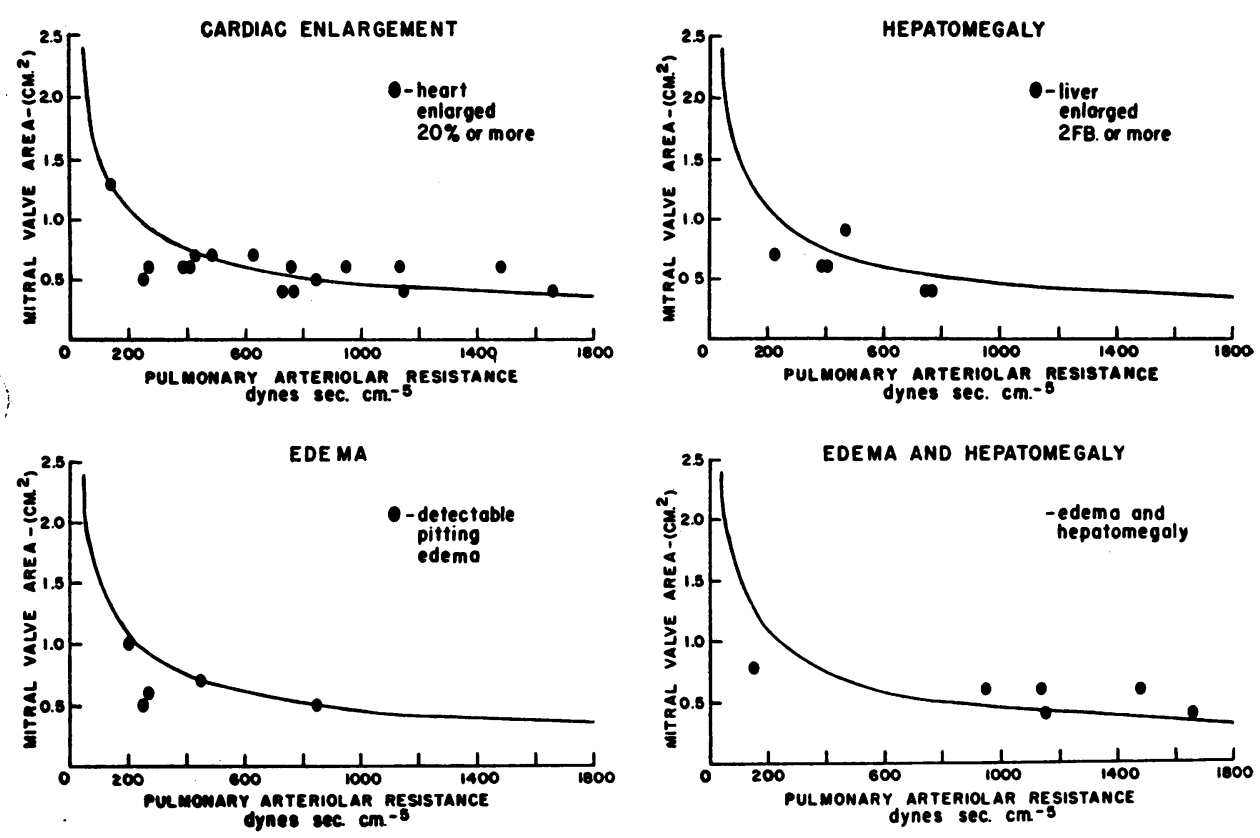

FIG. 3.-Relation of mitral valve area and pulmonary arteriolar resistance to physical findings in mitral stenosis. Reprinted from Lewis et al. (1952).

hepatomegaly, and a persistently high jugular venous pressure usually mean the disease has progressed far beyond mechanical obstruction of a valve, to involve the lungs, myocardium, and systemic organs.

A word on the mitral diastolic murmur is appropriate here. Some of its intensity depends on the amount of blood flowing through the valve. Therefore loudness of murmur tells nothing about the severity of stenosis, but simply that the valve is diseased. It may be very loud early in the disease when output is normal; conversely it may be absent in the terminal stages. In fact its absence when other incontroversible evidence of mitral stenosis is present is a solemn warning of the severity of the stenosis.

The disease may conveniently be divided into four stages as proposed for a group of patients by Lewis et al. (1952).

Group I. The valve area was greater than $1.3 \mathrm{sq} . \mathrm{cm}$. and pulmonary resistance normal. The only symptom was mild exertional dyspnœa, and there was no evidence of right ventricular failure.

Group II. The valve area was 0.5 to $1.1 \mathrm{sq} . \mathrm{cm}$. and pulmonary resistance was up to four times normal. Severe respiratory symptoms and paroxysmal pulmonary œedema predominated, but there was no right ventricular failure.

Group III. The valve area was 0.4 to $0.7 \mathrm{sq} . \mathrm{cm}$. and resistance four to seven times normal. These patients were in the balanced state and often could do light work without respiratory or peripheral congestive symptoms, although fatigue was common.

Group $I V$. The valve area was 0.4 to $0.6 \mathrm{sq}$. cm., and resistance seven to twelve times normal. These patients had both severe respiratory symptoms and right ventricular failure.

A more elusive problem is that of the incompetent mitral valve. As a predominantly pure condition it is rather uncommon, and any remarks are accordingly brief.

There are three apparent physiological adjustments and stages to a leaking mitral valve. (1) The left ventricle may pump enough blood to deliver a normal output despite the amount regurgitating into the atrium. (2) The left ventricle may pump only a normal or slightly increased amount of blood which must be distributed to the leak and to the aorta with a resultant decrease in blood 
supplied to the body. (3) This lowered output may be delivered at a high ventricular diastolic pressure, i.e. " failure" has occurred.

Which situation arises in a given patient depends primarily on the state of the myocardium and secondarily on the size of the regurgitant area.

Symptoms will depend on which adjustment takes place: in the first, no symptoms; in the second, undue exertional fatigue, about which more will be said below; and in the third, symptoms of left ventricular failure. If the third stage persists long enough, full-blown pulmonary vascular disease may develop and the clinical picture greatly resembles advanced mitral stenosis.

One of the commonest forms of mitral disease is that in which both stenosis and regurgitation are significant. Understanding of this disorder rests on two findings, the principles of which were discussed earlier: (1) the degree of stenosis is usually moderate $1.5-2 \mathrm{sq} . \mathrm{cm}$.; (2) the pressure-flow relationship for a 2 sq. $\mathrm{cm}$. valve is the same whether or not there is incompetence. Pulmonary arterial pressure, pulmonary capillary pressure, and total left ventricular output are almost identical. Valve area seems to predict how much blood gets into the ventricle. The obvious corollary of this is that systemic blood flow must be reduced whenever there is a significant regurgitation along with stenosis. The usual estimation is a 50 per cent leak, the other half being delivered to the body. This is the key to understanding mixed mitral disease. The major physiological defect is a very low cardiac output. There is only a moderate pulmonary capillary hypertension as in a pure moderate stenosis, a severe pulmonary arterial hypertension is uncommon, and the signs of right ventricular failure are rare.

From this physiological pattern, it is hard to predict any concrete clinical picture and such was borne out on attempted correlation of the two. The most striking feature, and one from which all physicians naturally shy, was that of limited physical capacity-patients were always tired, fatigued, weak, and unable to work. Some had moderate dyspnœa, some had paroxysmal attacks. And no patients had œdema or severe venous congestion. Certainly this could be the picture of an illness characterized mainly by poor blood flow without any great rise of pulmonary or systemic venous pressures. This is comparatively rare in medicine and is seen usually only in myxœdema and uncomplicated atrial septal defect. Occasionally some of these patients develop left ventricular failure, usually related to a smouldering myocarditis. This further chronic rise of pulmonary capillary pressure may lead to the whole pattern of dyspnœa, orthopnœa, etc., and thus as with pure regurgitation, in its end stage, resemble advanced pure mitral stenosis.

\section{SUMMARY}

In mitral stenosis, circulatory changes result from one or two obstructions to blood flow-the stenosed mitral valve with or without narrowed pulmonary arterioles. This causes pressure to rise behind each and for flow to decrease through them. This becomes significant for the mitral valve when its area is 25 per cent or less of normal, and for the pulmonary arterioles when the resistance is about five times normal.

Pulmonary symptoms are the result of pulmonary capillary hypertension with intra-alveolar transudation of fluid. This situation arises usually when the valve area is 25 per cent of normal or less and severity of symptoms generally parallels severity of stenosis. Peripheral congestive symptoms result from the effects of pulmonary arterial hypertension on right ventricular function and on blood flow.

Pure mitral regurgitation can be associated with normal or abnormal systemic output and left ventricular function. Symptoms are related accordingly.

In mixed mitral disease, the stenosis is seldom less than $25-40$ per cent of normal in area. The pulmonary pressure-flow equilibrium is related to the degree of stenosis and the systemic output to the degree of regurgitation.

Symptoms depend on the fact that the cardiac output is greatly decreased, while pulmonary and peripheral venous pressures are not unduly raised. Fatigue is usually prominent, dyspnoa usually moderate, and peripheral congestive signs usually absent. 
This paper is based on a lecture given in London in 1953.

\section{REFERENCES}

Bailey, C. P. (1949). Dis. Chest, 15, 377.

Baker, C., Brock, R. C., and Campbell, M. (1950). Brit. med. J., 1, 1283.

Gorlin, R., and Gorlin, S. G. (1951). Amer. Heart J., 41, 1.

, Lewis, B. J., Haynes, F. W., Goodale, W. T., Sawyer, C. G., Dow, J. W., and Dexter, L. (1951a). Amer. Heart J., 41, 30.

, Lewis, B. M., Haynes, F. W., Spiegl, R. J., and Dexter, L. (1951b). Amer. Heart J., 41, 834.

Harken, D. E., Dexter, L., Ellis, L B., Farrand, R. E., and Dickson, J. F. (1951). Ann. Surgery, 134, 722.

Lewis, B. M., Gorlin, R., Houssay, R. W. J., Haynes, F. W., and Dexter, L. (1952), Amer. Heart J., 43, 2. 